\title{
Economics
}

2015; 4(6): 112-117

Published online November 20, 2015 (http://www.sciencepublishinggroup.com/j/eco)

doi: 10.11648/j.eco.20150406.13

\section{Descriptive Study of 2013 China per Capita Wage in Logistics and Transportation Industry}

\author{
Jie Zhu, Ruoling Zhang, Binbin Fu, Renhao Jin
}

School of Information, Beijing Wuzi University, Beijing, China

Email address:

Renhao.jin@outlook.com (Renhao Jin)

\section{To cite this article:}

Jie Zhu, Ruoling Zhang, Binbin Fu, Renhao Jin. Descriptive Study of 2013 China per Capita Wage in Logistics and Transportation Industry. Economics. Vol. 4, No. 6, 2015, pp. 112-117. doi: 10.11648/j.eco.20150406.13

\begin{abstract}
This paper does a descriptive study on 2013 area level per capita wage in logistics and transportation industry data in China. The per capita wage value is found to have increased over 11 years with annual increasing rate 13.9\%. However, China per capita value is still less than western countries. The spatial autocorrelations are found in the area per capita wage data, and area per capita wage data is found to be high correlated with area per capita GDP data and area per capita wage in employment.
\end{abstract}

Keywords: China per Capita Wage, Area per Capita Wage, Area per Capita GDP, Spatial Distribution

\section{Introduction}

Recently years, China economic has attracted many researchers in the world. China's total GDP has ranked in the second in the world, and some economists predict that China's GDP will catch up United States' within 15 years. Over 30 years, China's total GDP have increased by more than $7 \%$ every year, and the logistics and transportation industry benefits a lot from the economic growth. There is a close link between the country's economic growth and the logistics and transportation industry growth. The development of logistics industry also can speed up the growth of China economic in the way of offering more job opportunities, boosting the country trading volume. For example, recently in China a lot of E-Commerce companies have made high growth in trading, and their successes is highly dependent on the development of Internet and logistics industry. On the other hand, the area total GDP should high correlated with its level of logistics and transportation industry. However, the developing level of logistics industry is not easily to assess, thus per capita wage in logistics and transportation industry are used in this paper as an important factor.

This paper does a description study on China per capita wage in logistics and transportation industry. The data used in this paper are obtained from China Statistical Yearbook, published by National Bureau of Statistics of China.

There are 27 provinces and 4 municipalities directly under the Central Government of China mainland. Beijing, Shanghai, Tianjin, Chongqing are the four municipalities, and Beijing and Shanghai are two very important cities in China and the World. Beijing is located in the north of China, which is the center of North China and capital of China. Shanghai is in the east of China, and the areas around Shanghai is the richest part in China.

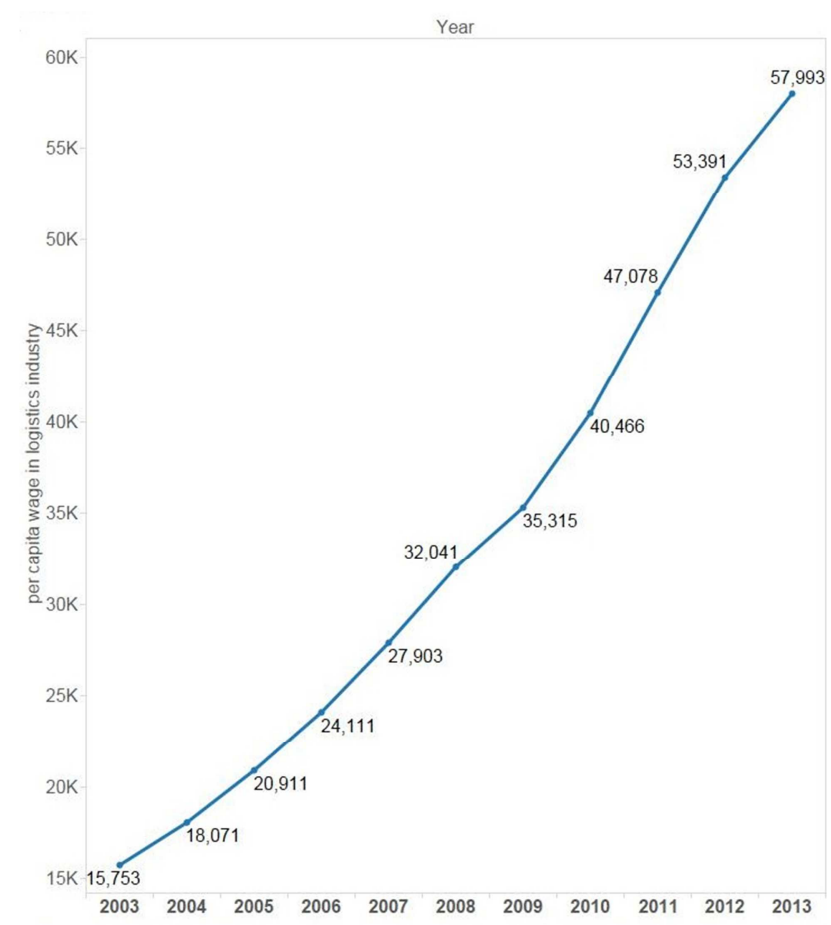

Figure 1. The China per capita wage in logistics and transportation industry from 2003 to 2013. The unit of per capita wage is China Yuan. 


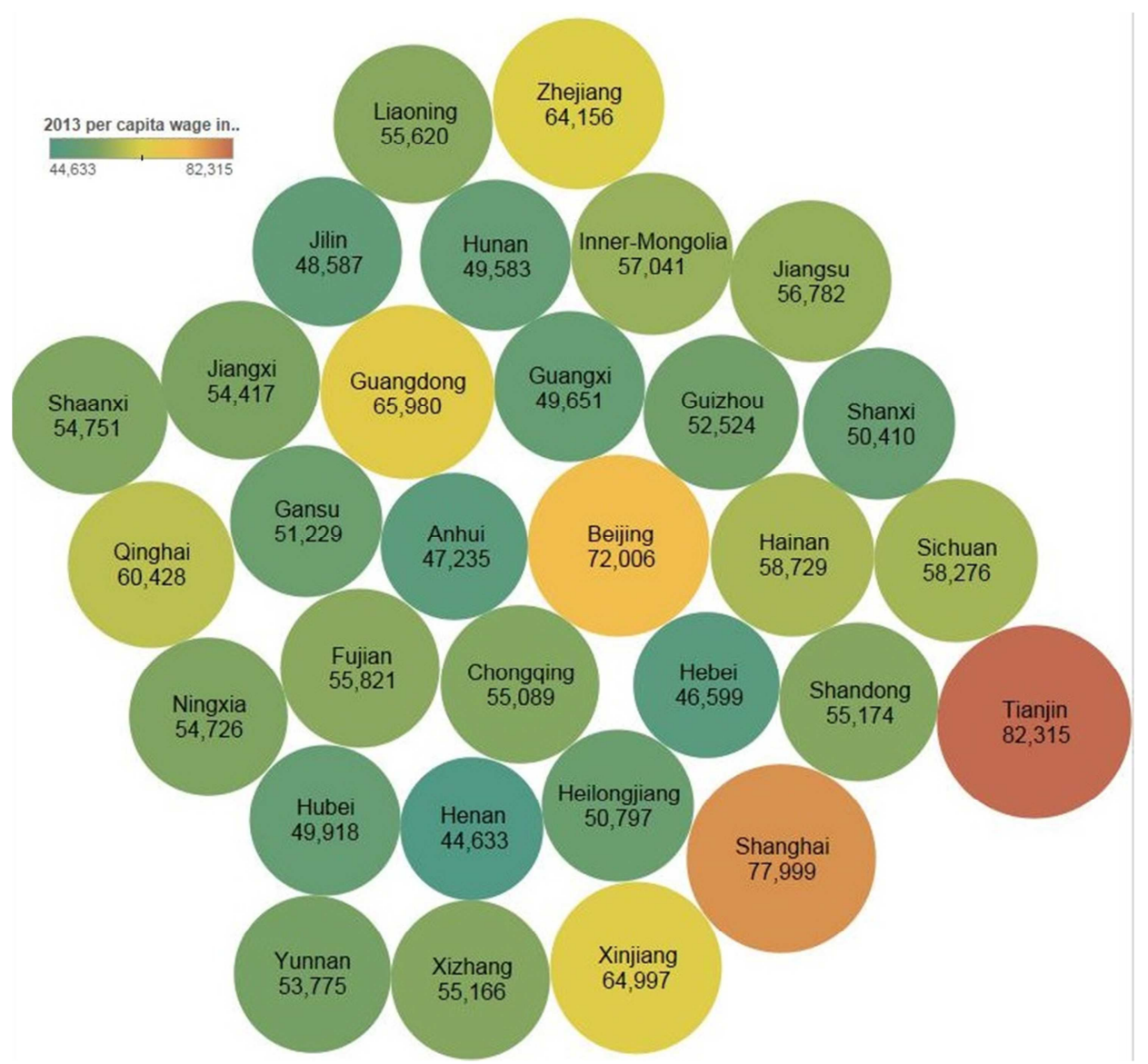

Figure 2. The Bubble Chart of area per capita wage in logistics and transportation industry. The size of bubble is proportional to the value scale of capita wage of employment (Unit: China Yuan), and the Color Indicates for the value are shown in the left head of the Chart.

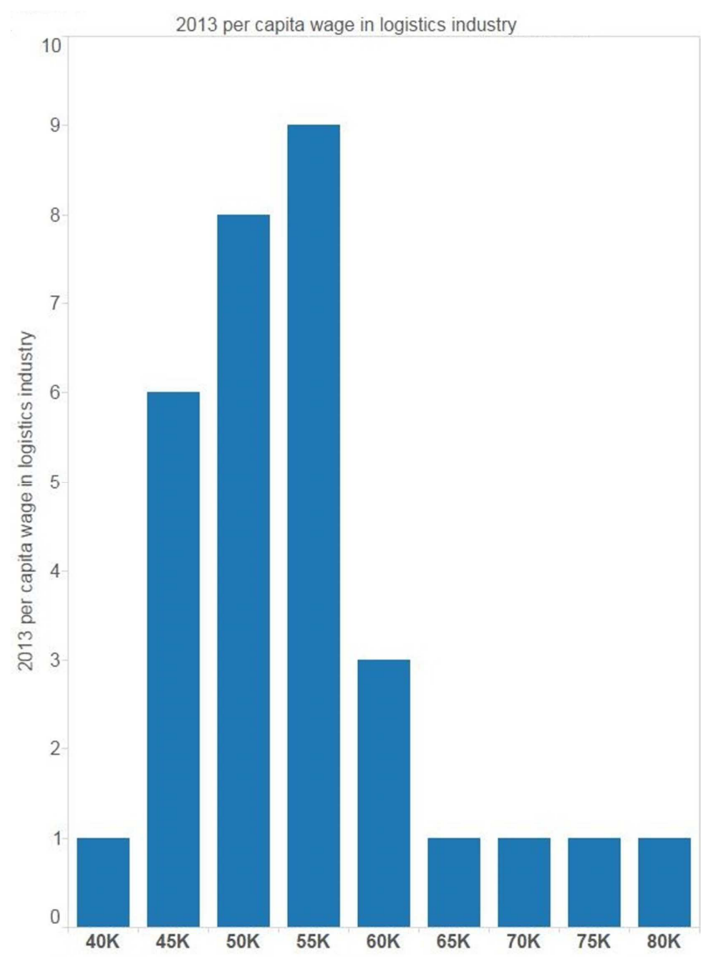

Figure 3. The histogram plot of area per capita wage in logistics and transportation industry.
As shown in Figure 1, from 2003 to 2013, China per capita wage in logistics and transportation industry is always in rising status, ranging from 15,753 China Yuan in 2003 to 57,993 China Yuan in 2013. The average annual increasing rate is $13.9 \%$, which is relative high comparing with other countries. It also indicates that the life level of Chinese people is improving. This result also matches the rising the China's total GDP, and in 2007 and 2010, China catch up with Germany and Japan respectively.

\section{The Area per Capita Wage in Logistics and Transportation Industry of 2013}

The area level per capita wage in logistics and transportation industry are shown in the Figure 2, and it contains the wage data of 31 areas in China. The size of bubble is proportional to the value scale of per capita wage in logistics and transportation industry (Unit: China Yuan) at the corresponding area and year 2013. It can be seen from the plot that the per capita wage range from 44,633 China Yuan in Area Henan and 82,315 China Yuan in Area Tianjin. As the Color Indicates are shown in the left head of the Figure 2, the red color denote high wage, and the three areas of Beijing, Shanghai and Tianjin have higher wage, with the per capita 
wage $72,006,77,999$ and 82,315 China Yuan respectively. However, all other areas are below the amount of 70,000 China Yuan. The distribution of area per capita wage in logistics and transportation industry is shown in histogram plot in Figure 3, and it displays that for majority of areas their per capita wage are less than 64.997 China Yuan, which corresponds to the situation of a developing country.

The spatial distribution of area average area per capita wage in logistics industry is shown in Figure 4. It is easily found that the areas in the east coastline have high wage values but some areas in middle China have relative low wage values. In the map only Tianjin and Shanghai are in red color as they have values more than 77,000 China Yuan, but the areas (Hebei) around Tianjin has low wage values, while the areas around Shanghai (Jiangsu and Zhejiang) have high wage values. However, in all the spatial association can be generally found in the map.

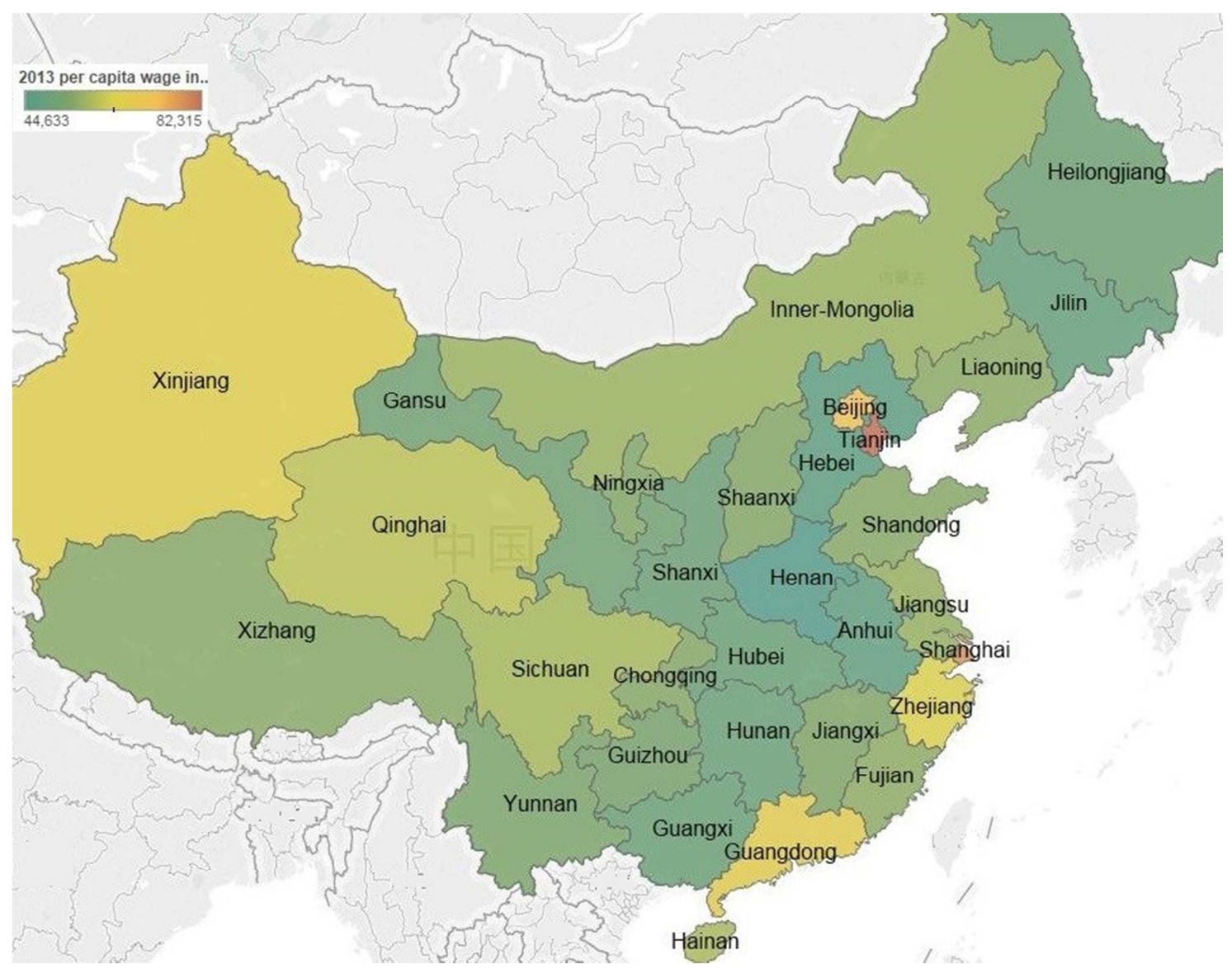

Figure 4. The heat map of average area per capita wage in logistics and transportation industry (Unit: China Yuan). The Color Indicates for the value size are shown in the left head of the Chart.

\section{The Correlation Between Area per Capita Wage in Logistics and Transportation Industry and per Capita GDP}

In this section, the correlation between area per capita wage in logistics industry and per capita GDP data is investigated. These two indexes are both often reflected the area economic status. The area per capita wage in logistics industry in this paper is only for the people who are engaged in this industry, while the area per capita GDP is calculated by including all the people of this area. The scatter plot of China area per capita wage in logistics and transportation industry and area per capita GDP in 2013 are shown in Figure 5. Generally, the areas with large per capita wage have large per capita GDP values, and these two indexes display a high positive correlation. Several outliers are found in the bottom of the plot, for example, the areas of Guizhou and Qinghai which have high per capita wage value in industry but have relative low per capita GDP value.

The Pearson product-moment correlation coefficient are used to measure the correlation between these two indexes. For $\mathrm{n}$ observations with two variables $\mathrm{X}$ and $\mathrm{Y}$, the Pearson correlation coefficient between them are defined as

$$
r_{x y}=\frac{\sum_{i}^{n}\left(x_{i}-\bar{x}\right)\left(y_{i}-\bar{y}\right)}{\sqrt{\sum_{i}^{n}\left(x_{i}-\bar{x}\right)^{2}} \sqrt{\sum_{i}^{n}\left(y_{i}-\bar{y}\right)^{2}}}
$$

where $\bar{x}$ and $\bar{y}$ are the mean value for $\left\{x_{1}, x_{2}, \ldots, x_{n}\right\}$ and $\left\{y_{1}, y_{2}, \ldots, y_{n}\right\}$ respectively. The Pearson coefficient for these two variables is calculated as 0.76 , which means a high correlation between China area per capita wage in logistics and transportation industry and area per capita GDP in 2013. 


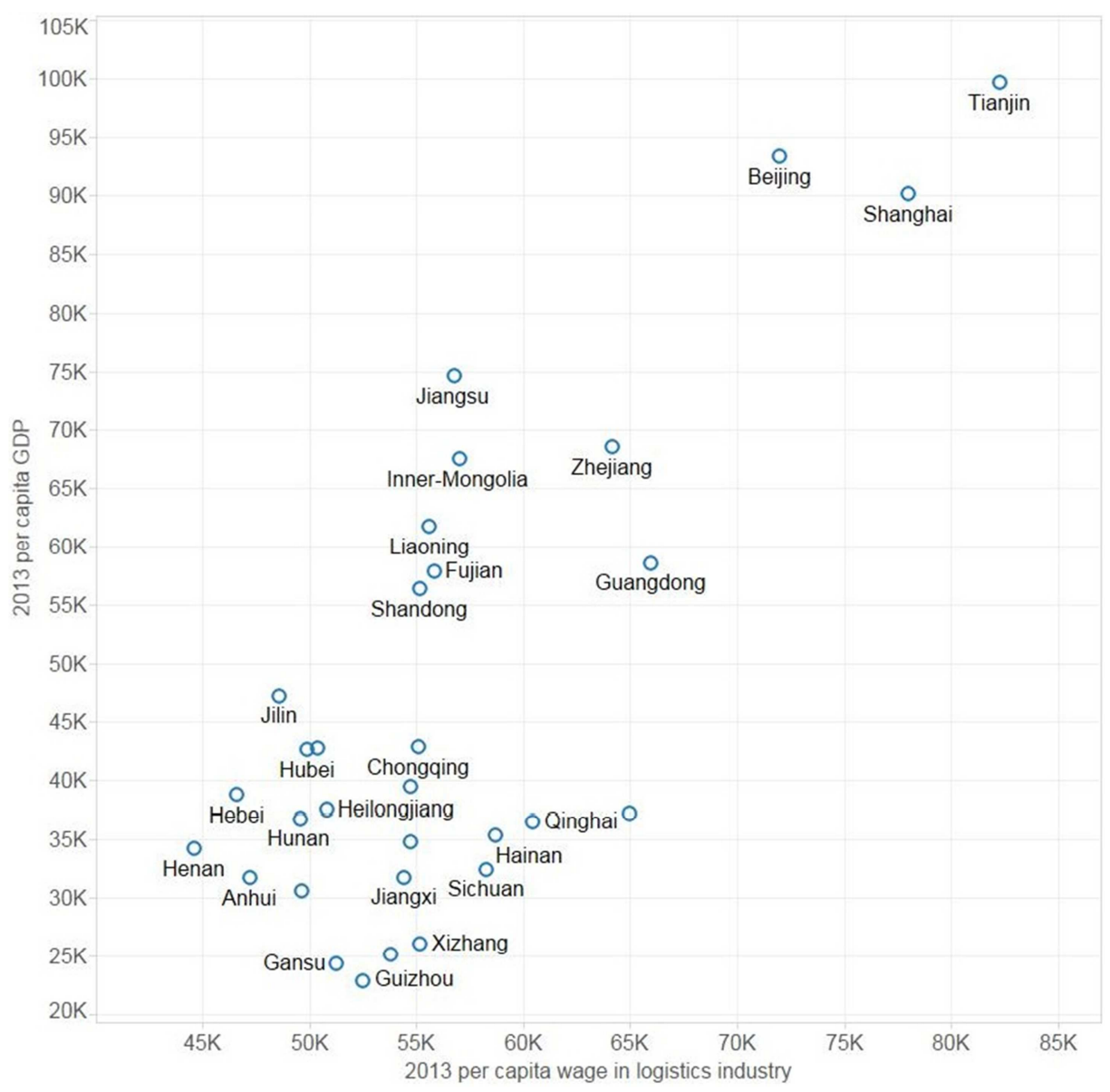

Figure 5. The scatter plot of China area per capita wage in logistics and transportation industry and area per capita GDP in 2013.

\section{The Correlation Between Area per Capita Wage in Logistics and Transportation Industry and per Capita Wage in Employment}

In this section, the correlation between area per capita wage in logistics industry and per capita wage in employment data is investigated. These two indexes are both the income indexes. The area per capita wage in logistics industry in this paper is only for the people who are engaged in this industry, while the area per capita wage in employment is calculated by including all the people in hired status. The scatter plot of these two indexes are shown in Figure 6. Generally, the areas with large per capita wage in logistics industry have large per capita wage in employment, and these two indexes display a high positive correlation. Almost none outliers are found in the plot.

The Pearson product-moment correlation coefficient are used to measure the correlation between these two indexes. The Pearson coefficient for these two variables is calculated as 0.81 , which means a high correlation between these two indexes. It also shows that the correlation between two wage variable are higher than that between per capita wage in logistics and per capita GDP, which also can be observed from Figure 5 and 6.

\section{Conclusion}

This paper firstly makes a plot of 11 years' China per capita wage in logistics and transportation industry data, and the growth trend on per capita wage can be found in these years. The average annual increasing rate of 11 years is $13.9 \%$, which is relative high comparing with other countries. Then a descriptive study was done on area per capita wage, and for majority of areas their per capita wages are found to be less than 70,000 China Yuan. A spatial association can be generally found in the area per capita distribution map, although some breaks are shown.

The correlation between area per capita wage in logistics and transportation industry and per capita GDP data are also investigated. Although several outliers are found in the scatter plot of these variables, the Pearson coefficient for these two variables is calculated as 0.76 . While the Pearson coefficient between per capita wage in logistics industry and per capita wage in employment is calculated as 0.81 , which shows that the correlation between two wage variable are higher than that between per capita wage in logistics and per capita GDP. 


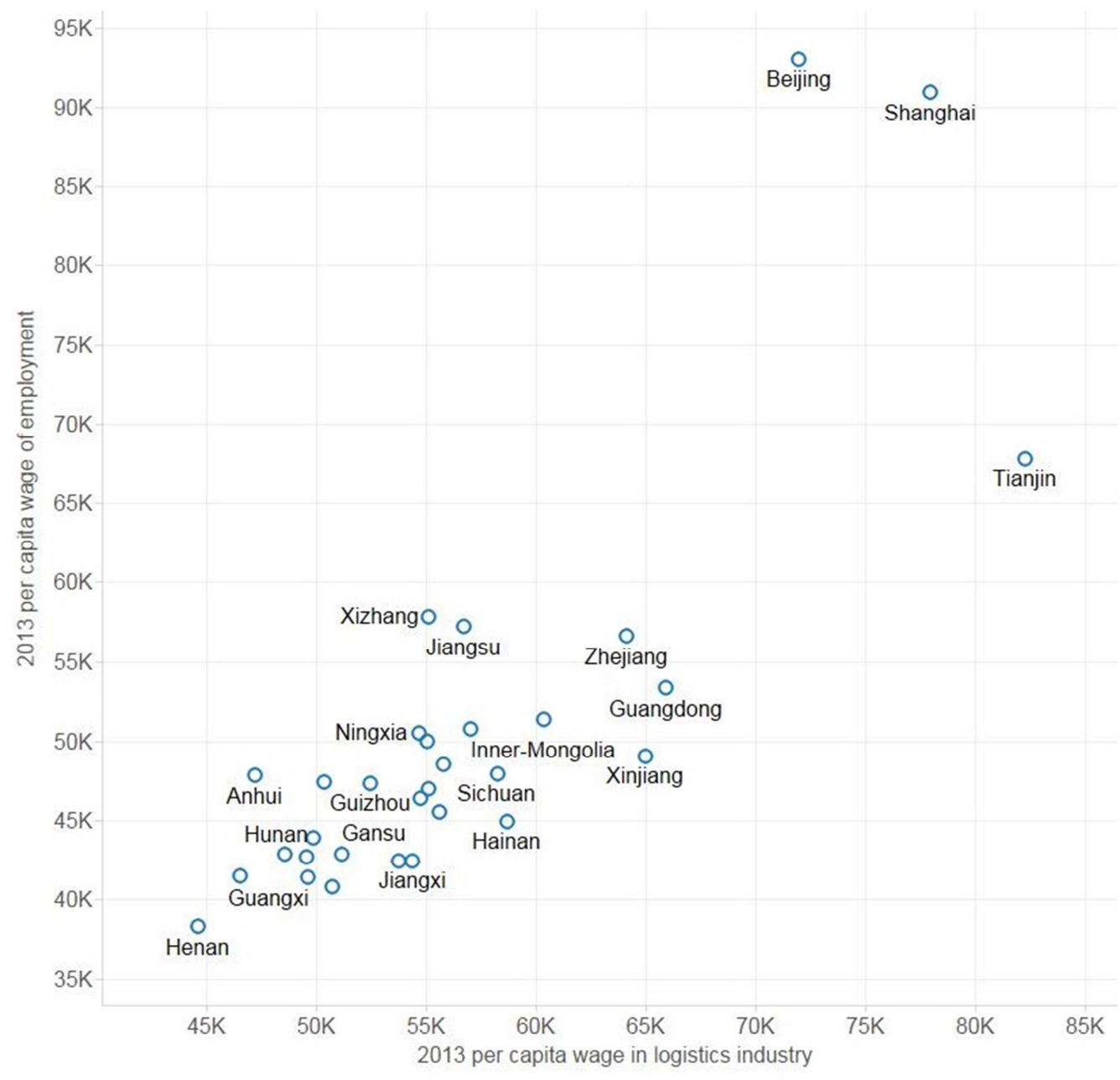

Figure 6. The scatter plot of China area per capita wage in logistics and transportation industry and area per capita wage in employment.

\section{Acknowledgements}

This paper is funded by the project of National Natural Science Fund, Logistics distribution of artificial order picking random process model analysis and research (Project number: 71371033); and funded by intelligent logistics system Beijing Key Laboratory (No.BZ0211); and funded by scientific-research bases---Science \& Technology Innovation Platform---Modern logistics information and control technology research (Project number: PXM2015_014214_000001); University Cultivation Fund Project of 2014-Research on Congestion Model and algorithm of picking system in distribution center (0541502703).

\section{References}

[1] Anselin, L. (1995). Local indicators of spatial association LISA. Geographical Analysis 27, 93--115.

[2] Besag, J. (1974). Spatial interaction and the statistical analysis of lattice systems. Journal of the Royal Statistical Society B 36, $192--225$.
[3] Getis, A. and Ord, J. K. (1992). The analysis of spatial association by use of distance statistics. Geographical Analysis 24, 189--206.

[4] Griffith, D. (1987). Spatial Autocorrelation: A Primer. Washington, DC: Association of American Geographers Resource Publication.

[5] Griffith, D. (1992). What is spatial autocorrelation? Reflections on the past 25 years of spatial statistics. l'Espace Ge'ographique 21, 265--280.

[6] Griffith, D. (1996). Spatial autocorrelation and eigenfunctions of the geographic weights matrix accompanying geo-referenced data. The Canadian Geographer 40, 351--367.

[7] "GDP (Official Exchange Rate)". CIA World Factbook. RetrievedJune 2, 2012.

[8] Dawson, Graham (2006). Economics and Economic Chenge. FT / Prentice Hall. p. 205. ISBN 9780273693512.

[9] Mardia, K. and Marshall, R. (1984). Maximum likelihood estimation of models for residual covariance in spatial regression. Biometrika 71, 135--146.

[10] Richardson, S. and He' mon, D. (1981). On the variance of the sample correlation between two independent lattice processes. Journal of Applied Probability 18, 943--948. 
[11] Tiefelsdorf, M. and Boots, B. (1995). The exact distribution of Moran's I. Environment and Planning. A 27, 985--999.

[12] SAS Institute Inc, (2008). SAS/STAT® 9.2 User's Guide: The variogram Procedure (Book Excerpt). NC: SAS Institute Inc, Cary.
[13] George Peck (2015). Tableau 9: The Official Guide. McGraw-Hill Education. 